\title{
Child Suicide Screening Methods: Are we Asking the Right Questions? A Review of the Literature and Recommendations for Practice
}

\author{
Arwen York \\ Brigham Young University, arwen.york@gmail.com \\ Barbara Heise \\ Brigham Young University, barbara-heise@byu.edu \\ BpHauldhiqnalcakdefitional works at: https://scholarsarchive.byu.edu/studentpub \\ ghambofung University prandonthatcher1@gmail.com
}

The College of Nursing showcases some of our best evidence based scholarly papers from graduate students in the Family Nurse Practitioner Program. The papers address relevant clinical problems for advance practice nurses and are based on the best evidence available. Using a systematic approach students critically analyze and synthesize the research studies to determine the strength of the evidence regarding the clinical problem. Based on the findings, recommendations are made for clinical practice. The papers are published in professional journals and presented at professional meetings.

\section{BYU ScholarsArchive Citation}

York, Arwen; Heise, Barbara; and Thatcher, Brandon, "Child Suicide Screening Methods: Are we Asking the Right Questions? A Review of the Literature and Recommendations for Practice" (2016). Student Works. 147.

https://scholarsarchive.byu.edu/studentpub/147

This Master's Project is brought to you for free and open access by BYU ScholarsArchive. It has been accepted for inclusion in Student Works by an authorized administrator of BYU ScholarsArchive. For more information, please contact scholarsarchive@byu.edu, ellen_amatangelo@byu.edu. 
Child Suicide Screening Methods: Are we Asking the Right Questions?

A Review of the Literature and Recommendations for Practice

Arwen C. York

An evidence-based scholarly paper submitted to the faculty of Brigham Young University

In partial fulfillment of the requirements for the degree of

Masters of Science

Barbara Heise, Chair

Brandon Thatcher

College of Nursing

Brigham Young University

September 2015

Copyright $@ 2015$ Arwen C. York

All Rights Reserved 


\begin{abstract}
Child Suicide Screening Methods: Are we Asking the Right Questions?

A Review of the Literature and Recommendations for Practice

\author{
Arwen C. York \\ College of Nursing, BYU \\ Masters of Science
}

This paper reviews five currently available suicide screening tools that might be appropriate for use with children aged 5 to 14 years old, evaluates the quality of these tools, and recommends which tools might be useful in primary care practice. To detect and prevent youth suicide, primary care nurse practitioners must be committed to child-centered care, recognize that suicidal thoughts and behaviors can develop very early in life, identify pertinent state and trait risk factors in pediatric patients, have knowledge of the strengths and limitations of available screening tools, and initiate and facilitate appropriate specialty care.
\end{abstract}

Keywords: child suicide, pediatric primary care, screening tools, youth suicide, pediatric suicide, pediatric psychiatry, pediatric mental health 


\section{ACKNOWLEDGMENTS}

First and foremost, I would like to express my appreciation for the help of my faculty mentor, Barb Heise. Your patience and input was invaluable in completing this project. I would also like to thank Brandon Thatcher for sharing his clinical expertise and guidance. Additionally, I want to extend my sincerest gratitude to the BYU College of Nursing for allowing me the opportunity to complete their wonderful FNP graduate program, which made this project possible in the first place. Most of all, I am grateful for the loving and steadfast support of my husband, Garett. Thank you. 


\title{
BRIGHAM YOUNG UNIVERSITY
}

Graduate mentor approval of evidence-based scholarly paper submitted by:

\author{
Arwen C. York
}

This evidence-based scholarly paper has been read by this faculty mentor and has been found to be satisfactory.

$11-9-20 / 5$

Date

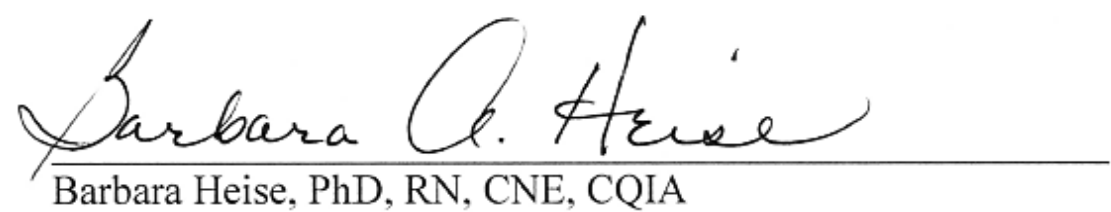

Associate Professor

Brigham Young University College of Nursing 


\section{BRIGHAM YOUNG UNIVERSITY}

As faculty mentor, I have read the evidence-based scholarly paper by Arwen C. York in its final form and have found that (1) its format, citations, and bibliographical style are consistent and acceptable and fulfill university and department style requirements; (2) its illustrative materials including figures, tables, and charts are in place; and (3) the final manuscript is satisfactory and is ready for submission to the College of Nursing.

$11-9-2015$

Date

Accepted for the College

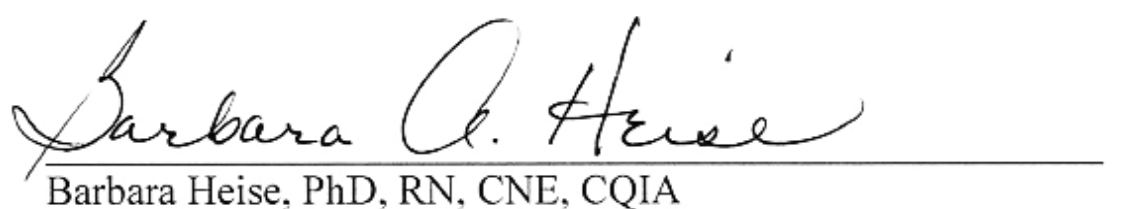
Associate Professor

Brigham Young University College of Nursing

Mary Willians, $\mathrm{RN}, \mathrm{PhD}$

Associate Dean for Graduate Studies and Scholarly Works and Contribution to the Discipline

Brigham Young University College of Nursing 


\section{LIST OF TABLES}

Table 1: Selected Screening Tools for Mental Health Disorders in Children...................15

Table 2: Selected Pediatric Suicide Screening Tools....................................16 


\section{TABLE OF CONTENTS}

Child Suicide Screening Methods: Are we Asking the Right Questions?

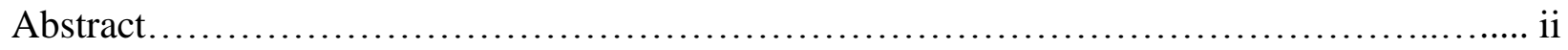

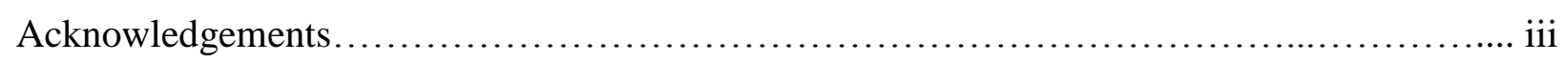

Graduate Mentor Approval..........................................................iv

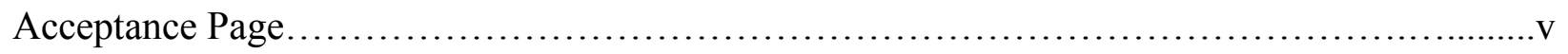

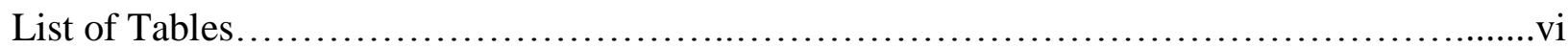

Manuscript: Child Suicide Screening Methods: Are we Asking the Right Questions? A Review

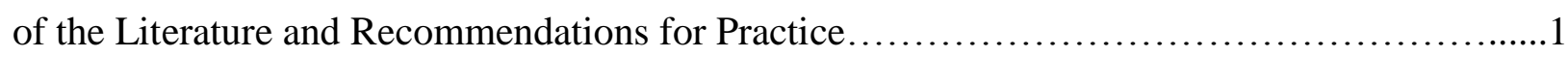

Introduction............................................................. 2

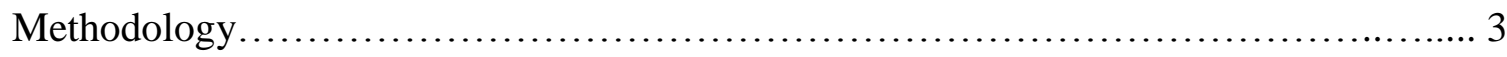

Identification of Studies............................................. 3

Inclusion/Exclusion Criteria......................................... 3

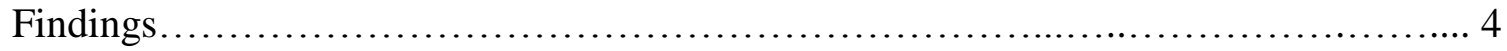

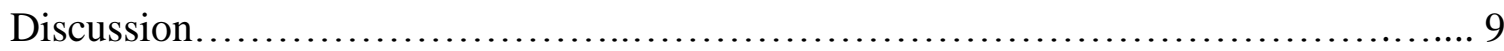

Conclusion........................................................... 10

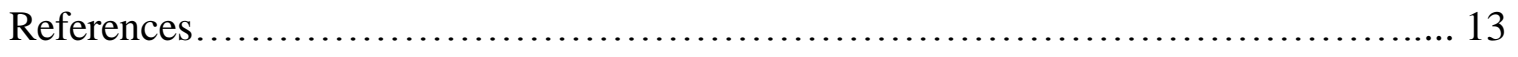

Tables................................................................... 15 


\section{Child Suicide Screening Methods: Are We Asking the Right Questions?}

A Review of the Literature and Recommendations for Practice

\section{Introduction}

Suicide in young children is more prevalent than many practitioners might think. In 2010, the rate of suicide among 5- to 14-year-olds in the United States (U.S.) was 0.7 per 100,000, which translates to 378 deaths annually. ${ }^{1-2}$ Mortality data from the 2013 National Vital Statistics System attributed 395 deaths in the 5-14 year old age group to intentional self-harm (suicide). ${ }^{3}$ By comparison, in the 5 to 9 and the 10- to 14-year-old age groups there were 342 deaths and 414 deaths respectively in $2013^{4}$ from motor vehicle accidents (the number one cause of unintentional injury deaths). Major depressive disorder (MDD), a leading risk factor for suicide, is estimated to occur in 2.8 percent of children under 13 years of age. ${ }^{5}$ A child might be diagnosed with MDD when he or she displays a persistent combination of sadness, irritability, and anhedonia for over 2 weeks. Concurrent symptoms can include social isolation; declining school performance; anger, sleep, or appetite disturbances; and complaints of nonspecific pain. ${ }^{5}$

Primary care nurse practitioners and other health care providers are in an ideal position to both detect the unique presentation and characteristics of suicidal tendencies in depressed children and facilitate early referral and treatment. However, actual or perceived time constraints, lack of resources, and provider inexperience are all potential barriers to the screening, assessment, and referral of at-risk patients. Practitioners are sometimes hesitant to screen for suicidality in children due to concern that broaching the topic might encourage suicidal behaviors. However, there is no evidence that screening for suicidality in children is harmful. ${ }^{6}$ Furthermore, studies have found that the majority of questioned children and their parents support the practice of routine screening in a variety of settings. ${ }^{7-8}$ Screening can also 
have positive predictive value; one study found that children between the ages of $8-12$ who had one or more positive responses to a three question "Risk for Suicide Questionnaire" were 3.5 times more likely to have repeat psychiatric visits to the emergency department (ED) within 1 year. ${ }^{9}$

Screening older adolescents and adults for depression and suicidality has been integrated into routine practice for some time. The American Academy of Pediatrics recommends that primary care providers assess adolescents for suicidality during annual well child checks, ${ }^{10}$ and the U.S. Preventative Services Task Force (USPSTF) provided a type "B" recommendation for annual depression screening in adolescents age 12-18 - meaning the USPSTF is highly certain of at least moderate benefit. ${ }^{5}$ However, little evidence is available to determine whether routine screening for suicide risk in children younger than 12 is indicated. ${ }^{5,7}$ Although the USPSTF does not recommend routine screening of children 7-11 years old, it does recommend screening for MDD in a child of any age when he or she has one or more of four major risk factors: parental depression, comorbid mental illness, comorbid chronic physical illness, or a history of a major negative life event. ${ }^{5}$ These children might also be at risk for other psychopathology and suicide even if they do not present with MDD. Comorbid depression is estimated to be a factor in about 50-79\% of suicide attempts, ${ }^{11}$ and so screening only for MDD might exclude a sizeable number of children at risk for suicide for other reasons such as negative life events. Practitioners must look at each child individually, along with his or her state and trait risk factors. The inclusion of a brief suicide screening tool as part of the routine examinations of at-risk children could help signal the development of dangerous thoughts or actions and aid early intervention.

Once an at-risk child is identified, the USPSTF did not find enough evidence to recommend any one screening tool above others to assist with further evaluation. ${ }^{5}$ In fact, a 2009 
literature review of MDD screening tools found that the tools reviewed were less effective when used for children younger than age 12 when compared to their use in older populations. ${ }^{6} \mathrm{~A}$ cursory internet search can reveal dozens of validated screening measures appropriate for use in the primary care setting designed to detect and assess a wide variety of mental health or behavioral issues, with question types ranging from open-ended to specific. Some examples can be found in Table 1. The majority of these tools were also listed in a 2013 Journal for Nurse Practitioners article, in which nurse practitioners providing mental health services to children reported the tools they used most commonly in clinical practice. ${ }^{12}$ Although these tools are useful for detecting MDD and other important mental health disorders in children who are not yet suspected of being at risk for suicide, this review will focus on suicide-specific screening tools that can be utilized in the pre-adolescent population (defined here as approximately 5-14 years old). The term "suicidality" here refers to any thought or action related to taking one's own life, which might range from passive suicidal thoughts to fully realized lethal attempts. Screening tools were evaluated using two main efficacy measures: sensitivity, meaning the tool has the ability to correctly identify individuals who are truly at risk; and specificity, meaning the tool differentiates between those who are at risk and those who are not, which helps prevent false positives. $^{13}$

For busy practitioners, it can be difficult to quickly identify a suicide-risk screening tool that is age-specific, convenient to administer, freely available, and highly reliable. ${ }^{9}$ The purpose of this paper is to review the literature regarding currently available child suicide screening tools; evaluate and compare their effectiveness, convenience, and psychometric quality; and recommend which tools appear to be most appropriate for use within the primary care setting.

\section{Methods}


A literature search of the electronic databases CINAHL, Health and Psychosocial Instruments, MEDLINE, PsycINFO, and PsycTESTS was conducted. The search was limited to English language articles published between January 2010 and March 2015, focusing on suicide screening techniques appropriate for use with pre-adolescent children in the primary care setting. Subject search terms used were child, youth, suicide, screening, diagnosis, and detection. This search yielded 280 articles. Of these, 20 article abstracts appeared to evaluate the merits of specific screening tools within the younger pediatric population, and were selected for further review. Additional articles that were frequently referenced in the literature review but were outside of the 5-year time frame were considered, particularly those regarding seminal and widely used screening tools. Studies that presented data in a way that could not be tested for methodological quality, e.g. specificity and sensitivity, were excluded. Studies that did not discuss the utility of the screening tool within the pediatric age group or offer any insight into screening children for suicidality in primary care were also excluded, as were lengthy interviewstyle screening tools requiring specialized training. Ultimately, five pediatric suicide screening tools mentioned in these articles were selected for discussion. This review aims to identify convenient, psychometrically sound tools that can be easily utilized by primary care providers.

\section{Findings}

There are multiple methods used to screen for suicidality in children. Basic formats include clinician guided interviews, parent reporting measures, and child self-reporting tools. The majority of clinician guided interviews require time and specialized training to administer. Several were not considered because their requisite specialized training made them unfeasible for use in primary care. Five pediatric-specific suicide screening tools were deemed appropriate for 
the primary care setting and are examined below. The format, length, recommended age group, and accessibility of each tool are summarized in Table 2.

\section{Ask Suicide Screening Questions}

The Ask Suicide Screening Questions tool (ASQ) was developed after testing 17

questions among 524 ED patients ages 10-21, without parents present. Of these youth, 344

presented with medical/surgical complaints and 180 presented with psychiatric complaints. The four questions found to have the highest sensitivity (96.9\%) and specificity (87.6\%) for suicide risk were subsequently combined to create a brief questionnaire. ${ }^{14}$ The four brief questions are as follows:

1) In the past few weeks, have you felt that you or your family would be better off if you were dead?

2) In the past few weeks, have you wished you were dead?

3) In the past week, have you been having thoughts about killing yourself?

4) Have you ever tried to kill yourself? ${ }^{14}$

This tool was found to have a high negative predictive value (NPV) (i.e. the likelihood that patients who screened negative are actually not at risk for suicide) of $99.7 \%$ for medical/surgical patients and $96.9 \%$ for psychiatric patients. The ASQ's positive predictive value (PPV) (i.e. the probability that patients who screened positive are actually at risk for suicide) was $71.3 \%$ for psychiatric patients. However, the ASQ's PPV was only $39.4 \%$ for medical/surgical patients.

\section{Risk for Suicide Questionnaire}

Ballard and colleagues $(2013)^{9}$ evaluated the association between one or more positive responses to the Risk for Suicide Questionnaire (RSQ) with increased odds of psychiatric 
hospitalization and repeated visits to the ED in a cohort of 442 children, aged 8-18 years old, who presented to the ED with a psychiatric chief complaint. Like the ASQ, the RSQ is comprised of 4 questions:

1) Are you here today because you tried to hurt yourself?

2) In the past week, have you been having thoughts about killing yourself?

3) Have you ever tried to hurt yourself in the past (other than this time)?

4) Has something very stressful happened to you in the past few weeks (a situation very hard to handle) $?^{9}$

Among 8-12 year olds, a positive response to any of the first three questions on the RSQ was associated with a 3.5 fold greater incidence of repeat psychiatric visits to the ED within 1 year. The questions were directed to the child, though often in the presence of a caregiver. ${ }^{9}$ The RSQ was originally developed and validated by Horowitz and colleagues in a 2001 study $^{15}$ and was found to have a sensitivity of $98 \%$, a specificity of $37 \%$, a PPV of 55\%, and an NPV of $97 \%$.

\section{The Mood and Feelings Questionnaire}

The Mood and Feelings Questionnaire (MFQ) is a common depression screening tool designed for children ages 7-17. It is designed to assess depressive disorder using 33 items, four of which specifically screen for suicidal ideation (SI). Hammerton and colleagues ${ }^{16}$ combined these four items into the MFQ-SI in 2004. They examined the concurrent and predictive validity of this tool by administering it to 294 children ages 9-17 from families containing one or more depressed parents. A total score for the MFQ-SI was derived by combining and totaling the highest scores from both the child and parent reports for the following items: "thought about death or dying," "thought family would be better off without self," "thought life was not worth 
living," and "thought about killing self," with each item coded 0 "not true," 1 "sometimes," or 2 "true" (total combined scores ranged from 0-8). ${ }^{16}$ When compared to the Child and Adolescent Psychiatric Assessment (CAPA), a specialized semi-structured interview used as a criterion standard, this study found that a MFQ-SI cut-off point greater than 2 out of a possible 8 points demonstrated a sensitivity of $57 \%$, a specificity of $75 \%$, a low PPV of $10 \%$, and an NPV of $97 \%$ for identifying current suicidal ideation. However, the MFQ-SI did demonstrate 73\% predictive validity for future suicidal ideation, when compared to the CAPA, when researchers assessed for SI a third time approximately 2 years later. ${ }^{16}$

\section{Treatment Emergent Activation and Suicidality Assessment Profile}

The Treatment Emergent Activation and Suicidality Assessment Profile (TEASAP) was created to be a relatively brief, comprehensive assessment of the range of clinical symptoms associated with behavioral activation related to antidepressant use in children and adolescents. ${ }^{17}$ The TEASAP assesses the presence of symptoms across five domains of behavioral activation: irritability, somatic complaints, impulsivity, mania, and violent or suicidal behavior. ${ }^{17}$ It is a 38 item, one-page parent report measure. Although this tool was envisioned to specifically screen for harmful behavioral activation after starting antidepressants, it could potentially be used to screen for suicidal behaviors in patients that are not taking antidepressants but possessing known risk factors (comorbidities, prior suicidal ideation, etc.).

Bussing et al. (2012) tested the psychometric properties of the TEASAP in a group of 57 youths aged 7-17 with Obsessive Compulsive Disorder (OCD). ${ }^{17}$ Because it measures psychometric properties for each of its five subscales as compared to varied criterion standard tools for each domain (activating symptoms are varied and include suicidality along with many other manifestations), it is not possible to report overall sensitivity and specificity for any one 
trait. Furthermore, disinhibition was the only subscale that was significantly associated with increased activating events. The authors noted that further research is needed to gain conclusive evidence of the utility of this tool for suicide screening in primary care. ${ }^{17}$

\section{Columbia Suicide Severity Rating Scale}

The Columbia Suicide Severity Rating Scale (C-SSRS) ${ }^{18}$ helps to differentiate between the domains of suicidal ideation and suicidal behavior. Four subscale constructs are measured: severity, intensity, behavior, and lethality of previous attempts. The tool includes two questions to assess suicidal ideation and four designed to detect suicidal behavior. The overall tool includes approximately 17 items. The principal psychometric evaluation of the C-SSRS encompassing pediatric populations was based on the findings of three major studies. Of note, these studies were not prospectively designed. The first included a future-suicide prevention study involving 124 former suicide attempters ages $12-18$. The second evaluated the efficacy of selective serotonin reuptake inhibitor (SSRI) antidepressant medications in a sample of 312 children ages 11-17 without a history of suicidal behavior. The third evaluated the C-SSRS in 237 adults ages 18 and older presenting to an ED for psychiatric treatment. ${ }^{18}$ Due to the variety of the three studies, psychometric results were varied. However, the sensitivity and specificity of the C-SSRS are high in the context of detecting suicidal ideation and behavior. Sensitivity and specificity in all three studies ranged from $93-100 \% .^{18}$

A version of the C-SSRS is available for pediatric or developmentally delayed patients, which rephrases some key concepts into more child-friendly wording, for example, saying "make yourself not alive anymore" instead of saying "kill yourself." However, school children between the ages of 7-17 were effectively given the regular C-SSRS in one 2012 trial, ${ }^{19}$ which found that the level of question comprehension depended on the cognitive abilities of the subject. The 
psychometric properties of the pediatric/developmentally delayed version of the tool have not been studied separately, although the differences between the two versions are minimal.

\section{Discussion}

\section{Brief child suicide assessments in primary care: The ASQ vs. the RSQ}

Originally created for the ED, ${ }^{9,14,15}$ the ASQ and RSQ four-question screening tools could easily be incorporated into primary care intake forms, or be administered by the medical staff gathering patient histories. The ASQ appears to be superior to the RSQ, due to the RSQ's low specificity of only $37 \%$, which might lead to a high amount of false positives, and result in wasted mental health services and resources. ${ }^{9}$

\section{Broad mental health screening tool with suboptimal suicidality screening ability: The MFQ}

The MFQ has the benefit of screening not only for suicidality, but also for a broad spectrum of other mental health disorders. It is also widely used and freely available online. However, in light of its sub-optimal sensitivity of $57 \%,{ }^{16}$ it lacks the ability to reliably pick up true cases of suicidality. For this reason, it is probably not the best choice for screening for suicidality in a child who the provider already knows to be at risk. However, the MFQ might be a good general tool for clarifying emotional disturbances and symptoms when a disorder is suspected but not yet known. ${ }^{16}$

\section{A work in progress: The TEASAP}

The TEASAP is a single tool created to simultaneously measure several different domains of behavioral activation. ${ }^{17}$ As such, the portions assessing each quality must be psychometrically measured against existing criterion standard tools. The overall findings in this study suggest that the tool does not perform as well as existing domain-specific tools except in the disinhibition domain, on which a high score did appear to be statistically associated with 
increased activating events. ${ }^{17}$ Clinicians are well aware that children at risk for suicidal behavior often present with multiple forms of concerning behavior, and measuring five behavioral domains with one tool would be preferable to measuring each domain individually. Although this tool is conveniently available online and relatively easy for parents to complete due to its short length and clear language, ${ }^{17}$ the results it provides are inconclusive and of questionable clinical significance. The TEASAP requires further research and revision to improve its accuracy and diagnostic value before it can be recommended for practical use in the clinical setting.

\section{Popular but not prospectively psychometrically proven: The C-SSRS}

Informal psychometric data suggests that the C-SSRS is a highly sensitive and specific test that has been successfully used in the younger pediatric population. ${ }^{18-19}$ Although prospective studies evaluating the psychometric properties of this tool are lacking, particularly for the pediatric/cognitively-impaired version, the C-SSRS has been widely recommended by many organizations, notably the Food and Drug Administration (FDA), the Joint Commission on Accreditation of Healthcare Organizations (JCAHO) Best Practices Library, and the Centers for Disease Control and Prevention (CDC), which recommends the C-SSRS in its suicide surveillance document. ${ }^{20}$ The C-SSRS recommends, but does not require, healthcare training to administer. Both the regular and pediatric/cognitively-impaired versions of the C-SSRS are available for free online. ${ }^{20}$ The C-SSRS could prove to be a feasible and useful asset as a screening measure for primary care providers to administer to high-risk children.

\section{Conclusion}

Pediatric suicide is a very real problem. Although many nurse practitioners might never care for a child who goes on to commit suicide, early detection and prevention should be the primary goal of conscientious providers who want to prevent a tragedy like this from occurring. 
Although the USPSTF does not recommend routine mental health screening for children under 12 years old, the agency does recommend screening any child at high risk. ${ }^{5}$

Brief instruments can be useful in identifying suicide risk, which then requires more indepth psychological evaluation and referral; however, when used independently, brief instruments are not especially thorough or informative. Examples of brief suicide risk screening tools that are reasonably well-validated, readily available, and convenient to administer include conversation-starting tools like the ASQ. On the other hand, brief tools that are highly sensitive but not particularly specific, such as the RSQ, could result in many false alarms and waste valuable time and resources, and are not recommended for use in clinical practice.

Other tools can be used to establish baseline levels of wellness or to monitor children's symptoms over time. The MFQ is an example of a tool with a broad sensitivity for many disorders, including suicidality to a lesser extent, which could easily be incorporated into well child intake paperwork. Using this tool could establish a helpful baseline for future visits or signal the need for more focused screening. Another tool that might be potentially useful in assessing children's baseline suicide risk is the C-SSRS. The C-SSRS comes in a few different versions that are widely recognized as being reputable measures of present suicidality and useful for monitoring the progression or regression of symptoms over time. This tool could be particularly helpful for children who are known to have previous suicide attempts or risk factors.

The need for further development and rigorous psychometric testing of pediatric-specific suicide screening tools is still a pressing issue. There are a limited number of research studies devoted to the development and assessment of suicide screening tools for young children, especially in the last 10 years. The quality, size, and psychometric soundness of the few available 
studies vary widely, making objective assessment of their clinical potential difficult, if not impossible, for actively practicing nurse practitioners.

Consequently, it is essential that practitioners use their clinical judgment in selecting an appropriate screening tool. It is important to remember that screening tools provide limited information when used alone, but can be very useful in signaling the need for further evaluation and psychiatric referral. Nurse practitioners should be mindful that once a problem is identified it is their responsibility to ensure the child receives appropriate mental health services. Even if they cannot safely provide the level of specialized pediatric psychiatric services suicidal children need, practitioners in the primary care setting can serve as coordinators of care, supporting patient compliance with their recommended treatment plans and ensuring continuity of care.

Moving forward, a common language and standard of care should be established and adopted by all primary care providers to aid in the assessment of the psychological wellbeing of children over time, so subtle changes and cries for help can be identified sooner. A commitment to child-centered and multidisciplinary care, knowledge of the strengths and limitations of available screening tools, perceptive assessment skills, and an awareness that self-destructive thoughts and behaviors can develop at a very early age are essential for nurse practitioners in detecting and preventing youth suicide. 


\section{References}

1. Howden L, Meyer J. Age and sex composition: 2010. Census briefs. http://www.census.gov/prod/cen2010/briefs/c2010br-03.pdf. Published 2010. Accessed March 29, 2015.

2. McIntosh JL, Drapeau CW. U.S.A. Suicide 2010: Official final data. American Association of Suicidology, Washington, DC. http://www.suicidology.org. Published 2012. Accessed March 29, 2015.

3. Deaths: Final data for 2013. Centers for Disease Control and Prevention National Vital Statistics System Web site. http://www.cdc.gov/nchs/data/nvsr/nvsr64/nvsr64_02.pdf. Last updated December 9, 2015. Accessed December 21, 2015.

4. Injury Prevention \& Control: Data \& Statistics (WISQARS): Ten Leading causes of death and injury 2013. Centers for Disease Control and Prevention Website.

http://www.cdc.gov/injury/wisqars/LeadingCauses.html. Last updated March 31, 2015. Accessed April 19, 2015.

5. Depression in Children and Adolescents: Screening.United States Preventive Services Task Force.

http://www.uspreventiveservicestaskforce.org/Page/Document/RecommendationStateme ntFinal/depression-in-children-and-adolescents-screening. Published March, 2009. Accessed March 29, 2015.

6. Williams SB, O'Connor EA, Eder M, Whitlock EP. Screening for Child and Adolescent Depression in Primary Care Settings: A Systematic Evidence Review for the US Preventive Services Task Force. Pediatrics. 2009;123(4):e716-e735.

7. Horowitz L, Ballard E, Teach SJ, et al. Feasibility of screening patients with nonpsychiatric complaints for suicide risk in a pediatric emergency department: a good time to talk? Pediatric Emergency Care. 2010;26(11):787-792.

8. Fox C, Eisenberg M, McMorris B, Pettingell S, Borowsky I. Survey of Minnesota Parent Attitudes Regarding School-Based Depression and Suicide Screening and Education. Maternal \& Child Health Journal. 2013;17(3):456-462.

9. Ballard ED, Horowitz LM, Jobes DA, Wagner BM, Pao M, Teach SJ. Association of Positive Responses to Suicide Screening Questions With Hospital Admission and Repeated Emergency Department Visits in Children and Adolescents. Pediatric Emergency Care. 2013;29(10):1070-1074.

10. Shain BN. Suicide and Suicide Attempts in Adolescents. Pediatrics. 2007;120(3):669676.

11. Horowitz LM, Ballard ED, Pao, M. Suicide screening in schools, primary care and emergency departments. Current Opinion in Pediatrics. 2009; 21(5); 620-627. 
12. Hawkins-Walsh E, Van Cleve S. The Pediatric Mental Health Specialist: Role Delineation. The Journal for Nurse Practitioners. 2013;9(3):142-148.

13. Reid M, Lachs MS, Feinstein AR. Use of methodological standards in diagnostic test research: Getting better but still not good. JAMA. 1995;274(8):645-651.

14. Horowitz LM, Bridge JA, Teach SJ, et al. Ask Suicide-Screening Questions (ASQ): A Brief Instrument for the Pediatric Emergency Department. Archives of Pediatrics \& Adolescent Medicine. 2012;166(12):1170-1176.

15. Horowitz LM, Wang PS, Koocher GP, et al. Detecting Suicide Risk in a Pediatric Emergency Department: Development of a Brief Screening Tool. Pediatrics. 2001;107(5):1133.

16. Hammerton G, Zammit S, Potter R, Thapar A, Collishaw S. Validation of a composite of suicide items from the Mood and Feelings Questionnaire (MFQ) in offspring of recurrently depressed parents. Psychiatry Research. 2014;216(1):82-88.

17. Bussing R, Murphy TK, Storch EA, et al. Psychometric properties of the TreatmentEmergent Activation and Suicidality Assessment Profile (TEASAP) in youth with OCD. Psychiatry Research. 2013;205(3):253-261.1.

18. Posner K, Brown GK, Stanley B, et al. The Columbia-Suicide Severity Rating Scale: Initial Validity and Internal Consistency Findings From Three Multisite Studies With Adolescents and Adults. American Journal of Psychiatry. 2011;168(12):1266-1277.

19. Prakash A, Lobo E, Kratochvil CJ, et al. An open-label safety and pharmacokinetics study of duloxetine in pediatric patients with major depression. Journal of Child and Adolescent Psychopharmacology. 2012;22(1):48-55.

20. Center for Suicide Risk Assessment. Columbia Suicide Severity Rating Scale: General Information. http://cssrs.columbia.edu/about_cssrs.html. N.D. Accessed May 27, 2015. 


\section{TABLES}

Table 1: Selected Screening Tools for Mental Health Disorders in Children

\begin{tabular}{|c|c|c|c|c|c|c|}
\hline Name of Tool & Screens for & Ages & $\begin{array}{l}\text { Number } \\
\text { of items }\end{array}$ & $\begin{array}{l}\text { Length } \\
\text { of time } \\
\text { to } \\
\text { complete }\end{array}$ & $\begin{array}{l}\text { Completed } \\
\text { by }\end{array}$ & Availability \\
\hline $\begin{array}{l}\text { Pediatric } \\
\text { Symptom } \\
\text { Checklist } \\
\text { (PSC) }^{1}\end{array}$ & $\begin{array}{l}\text { Any mental } \\
\text { health } \\
\text { condition }\end{array}$ & $3-16$ & 35 & 3 minutes & Parent & $\begin{array}{l}\text { Free online: } \\
\text { http://www.brightfutures.org/m } \\
\text { entalhealth/pdf/professionals/p } \\
\text { ed sympton chklst.pdf }\end{array}$ \\
\hline $\begin{array}{l}\text { Child Behavior } \\
\text { Checklist } \\
\text { (Parent Form) }^{2}\end{array}$ & $\begin{array}{l}\text { Any mental } \\
\text { health } \\
\text { condition }\end{array}$ & $6-18$ & 113 & $\begin{array}{l}10-20 \\
\text { minutes }\end{array}$ & Parent & $\begin{array}{l}\$ 475 \text { for Computer- } \\
\text { scoring starter kit for } \\
\text { ages } 6-18 \mathrm{w} / \\
\text { multicultural } \\
\text { options. } \\
\text { Can be purchased: } \\
\text { http://www.aseba.org/ }\end{array}$ \\
\hline $\begin{array}{l}\text { Mood and } \\
\text { Feelings } \\
\text { Questionnaire } \\
(\text { MFQ) })^{3}\end{array}$ & $\begin{array}{l}\text { Depression } \\
\text { (4 items also } \\
\text { screen for } \\
\text { suicidal } \\
\text { ideation) }\end{array}$ & $6-18$ & $\begin{array}{l}\text { 13-33 } \\
\text { (short } \\
\text { vs. long) }\end{array}$ & $\begin{array}{l}5-10 \\
\text { minutes }\end{array}$ & $\begin{array}{l}\text { Child; } \\
\text { parent } \\
\text { version } \\
\text { also } \\
\text { available }\end{array}$ & $\begin{array}{l}\text { Free online: } \\
\text { http://devepi.duhs.duke.edu/mf } \\
\text { q.html }\end{array}$ \\
\hline $\begin{array}{l}\text { Beck } \\
\text { Depression } \\
\text { Inventory for } \\
\text { Youth-II (BYI- } \\
\text { II) }\end{array}$ & $\begin{array}{l}\text { Depression } \\
\text { (severity) }\end{array}$ & $7-18$ & 20 & $\begin{array}{l}5-10 \\
\text { minutes }\end{array}$ & Child & $\begin{array}{l}\$ 81 \text { for manual. } \\
\$ 56.40 \text { for } 25 \text { test } \\
\text { booklets. Can be } \\
\text { purchased: } \\
\text { http://pearsonassess.com/haiwe } \\
\text { b/cultures/en- } \\
\text { us/productdetail.htm?pid=015- } \\
8014-197\end{array}$ \\
\hline $\begin{array}{l}\text { Children's } \\
\text { Depression } \\
\text { Inventory-2 }\end{array}$ & Depression & $7-17$ & 27 & $\begin{array}{l}15 \\
\text { minutes }\end{array}$ & $\begin{array}{l}\text { Child; } \\
\text { parent and } \\
\text { teacher } \\
\text { forms also } \\
\text { available }\end{array}$ & $\begin{array}{l}\$ 369 \text { for CDI } 2 \text { online } \\
\text { kit } \\
\text { CDI } 2 \text { manual, } 25 \text { self- } \\
\text { report/self-report } \\
\text { short/parent/teacher } \\
\text { online forms. Can be } \\
\text { purchased: } \\
\text { https://lecom.mhs.com/\%28S\% } \\
\text { 28w44qdv45oxs3ce1em2afo5} \\
\text { 5\%29\%29/inventory.aspx?gr=e } \\
\text { du\&prod=cdi2\&id=pricing\&R } \\
\text { ptGrpID=cdr }\end{array}$ \\
\hline
\end{tabular}

1.Jellinek MS, Murphy JM, Robinson J, et al. The Pediatric Symptom Checklist: Screening school-age children for psychosocial dysfunction. J Pediatr. 112;201-209:1988.

2. Achenbach, T. M. (1992). Manual for the Child Behavior Checklist/2-3 and 1992 profile. Burlington, VT: University of Vermont Department of Psychiatry.

3. Angold, A., Costello, E. J., Messer, S. C., Pickles, A., Winder, F., \& Silver, D. (1995) The development of a short questionnaire for use in epidemiological studies of depression in children and adolescents. International Journal of Methods in Psychiatric Research, 5, 237 - 249.

4. Beck, J. S., Beck, A. T., \& Jolly, J. B. (2001). Beck Youth Inventories. San Antonio, TX: Psychological Corporation

5. Kovacs M. The Children's Depression Inventory (CDI). Manual. North Tonawanda, NY: Multi-Health Systems; 1992. 


\begin{tabular}{|c|c|c|c|}
\hline $\begin{array}{l}\text { Screening } \\
\text { Tool }\end{array}$ & Format/Duration & $\begin{array}{l}\text { Recommended or } \\
\text { age ranges in study }\end{array}$ & How it can be obtained/associated cost \\
\hline $\mathbf{A S Q}^{13}$ & $\begin{array}{l}\text { Child self-report; } \\
4 \text { question } \\
\text { instrument }\end{array}$ & $10-21$ (study) & $\begin{array}{l}\text { (Free) available online: } \\
\text { http://archpedi.jamanetwork.com/journal.asp } \\
\underline{\text { “ (search for "ASQ," tool included under }} \\
\text { "supplementary materials"). }\end{array}$ \\
\hline $\mathrm{RSQ}^{8,14}$ & $\begin{array}{l}\text { Child self-report; } \\
4 \text { question } \\
\text { instrument }\end{array}$ & $8-18$ (study) & $\begin{array}{l}\text { (Requires journal subscription) All } 4 \\
\text { questions are listed in the original article. } \\
\text { Email Eballar3@jhmi.edu for additional } \\
\text { information. }\end{array}$ \\
\hline MFQ $^{15}$ & $\begin{array}{l}\text { Child self-report } \\
\text { 13-33 questions } \\
\text { (short vs. long) }\end{array}$ & 7-17; 9-17 (study) & $\begin{array}{l}\text { (Free) available online: } \\
\text { http://devepi.duhs.duke.edu/mfq.html }\end{array}$ \\
\hline TEASAP ${ }^{16}$ & $\begin{array}{l}\text { Parent report; } 38 \\
\text { questions }\end{array}$ & 7-17 (study) & $\begin{array}{l}\text { (Free) available online under "supplementary } \\
\text { materials" http://www.psy- } \\
\text { journal.com/article/S0165- } \\
1781 \% 2812 \% 2900516-1 / \text { abstract }\end{array}$ \\
\hline $\begin{array}{l}\text { C-SSRS } \\
18\end{array}$ & $\begin{array}{l}\text { Child self-report; } \\
6 \text { screening } \\
\text { questions and } \\
\text { approximately } 17 \\
\text { variable-format } \\
\text { items. }\end{array}$ & $7+$ (studies) & $\begin{array}{l}\text { (Free) Available online: } \\
\text { http://cssrs.columbia.edu/scales_practice_css } \\
\text { rs.html }\end{array}$ \\
\hline
\end{tabular}

